\title{
MANAGEMENT OF AEDES AEGYPTI USING GREEN SILVER NANOPARTICLES AND BOTANICAL EXTRACTS
}

\author{
Hassan Saeed ${ }^{1}$, Muhammad Tariq ${ }^{1}$, Asim Gulzar ${ }^{1}$, Zia-ur-Rehman Mashwani ${ }^{2}$, Muhammad Safian Bajwa ${ }^{1}$ \\ ${ }^{1}$ Department of Entomology, Pir Mehr Ali Shah Arid Agriculture University, Rawalpindi, Pakistan. \\ 2 Department of Botany, Pir Mehr Ali Shah Arid Agriculture University, Rawalpindi, Pakistan.
}

\section{A R T I C L E I N F O}

\section{Article history}

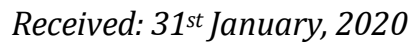

Revised: $19^{\text {th }}$ March, 2020

Accepted: 22 $2^{\text {nd }}$ March, 2020

\section{Keywords}

Yellow fever mosquito

Botanical extracts

Green synthesized silver

nanoparticles

LC50

Toxicity

\section{A B S T R A C T}

\begin{abstract}
The excessive use of insecticides has led to development of resistance in Aedes aegypti and negative impact on environment and non-target organisms. To overcome these problems, emphasis is being laid for alternatives, therefore, in the present study, the toxicity of eight plant extracts and their green synthesized nanoparticles were evaluated against $A$. aegypti. Clove extracts caused the maximum mortalities of $92 \%$ and $90 \%$ of $3^{\text {rd }}$ and $4^{\text {th }}$ instar larvae of $A$ aegypti followed by ginger causing $90 \%$ and $78 \%$ mortalities respectively. On the other hand, the minimum mortalities of these larvae were caused by neem and garlic extracts. In case of green silver nanoparticles, the maximum mortalities of $3^{\text {rd }}$ and $4^{\text {th }}$ instar larvae of $A$. aegypti were caused by clove followed by ginger while the minimum mortalities were caused by nanoparticles of datura followed by garlic. All the green silver nanoparticles caused mortalities of both the instars of the mosquito above $80 \%$ with few exceptions. Datura extracts showed the minimum LC 50 values after 72 hours of application followed by neem against the $3^{\text {rd }}$ and $4^{\text {th }}$ instar larvae of $A$. aegypti. The highest $\mathrm{LC}_{50}$ value was observed in case of ginger followed by clove and eucalyptus. In case of silver nanoparticles, the minimum $\mathrm{LC}_{50}$ values after 72 hours were recorded in case of datura, neem and garlic while the values were the maximum in case of clove and ginger. The $\mathrm{LC}_{50}$ values decreased with the passage of time.
\end{abstract}

Corresponding Author: Hassan Saeed

Email: hassan.saeed909@gmail.com

(C) 2020 EScience Press. All rights reserved.

\section{INTRODUCTION}

The yellow fever mosquito, Aedes aegypti (Diptera: Culicidae) is a vector of several arboviruses such as chikungunya virus (Leparc-Goffart et al., 2014), zika virus (Gutiérrez-Bugallo et al., 2019) and dengue virus (Morrison et al., 2019). Dengue is the most important mosquito borne disease (Li et al., 2019) and over 390 million humans are effected by dengue virus per year in the world (WHO, 2018). Dengue and zika fever do not have any specific medication as a cure, so the most important measure is to control the mosquitoes of these diseases. These control measures include the use of synthetic insecticides (Paul et al., 2006), essential oils (Pandiyan et al., 2019) and microorganism based insecticides (Vasantha-Srinivasan et al., 2019) against mosquitoes but the chemical based insecticides are 
commonly used (Manjarres-Suarez and Olivero-Verbel, 2013).

The major hindrance to the use of chemical insecticides is the development of resistance in the target mosquito (Kandel et al., 2019). The other problems associated with the application of synthetic insecticides are the adverse impact on the environment, non-target organisms and negative impact on human health (Hazra et al., 2017).

To overcome these problems, best alternative is the use of plant based insecticides which are environment friendly, safer for non-target organisms (Abbas et al., 2014) and less toxic to the ecosystem (Ghosh et al., 2012). Plant extracts have also been identified as strong repellent insecticides against mosquitoes (Misni et al., 2009). The plant extracts have been used in several ways for the management of mosquitoes. They have also been utilised as repellents in the form of oils against mosquitoes. Mosquito killing products like coils made from dried plant materials are also being used for the management of mosquitoes (Remia et al., 2017). In Java, plant synthesized incense has also been used routinely in order to repel mosquitoes (Sangat-Roemantyo, 1990). Green synthesized nanobased insecticides are getting more attention due to many advantages such as enhancing the efficacy of botanical insecticides with very low quantity and without resistance against target pest (Pavunraj et al., 2017). Nanoparticles are substances possessing smaller particle size and are widely used in biological and medical science (Iravani, 2011). Among various metal nanoparticles, the silver nanoparticles (AgNPs) have got more attention due to broad applications in different fields (Fouad et al., 2018) and being less harmful to the ecosystem (Suresh et al., 2014). Green based silver nanoparticles are a modern practice which increases the insecticidal effectiveness of plant extracts (Barnawi et al., 2019).

To overcome the issues coupled with the use of pesticides, emphasis is being laid to quest alternative strategies such as use of biopesticides which are environmentally friendly and economical. As little research has been done to control the mosquito with green synthesized nanoparticles, therefore, the current study was carried out to manage Aedes aegypti with plant extracts and their green synthesized silver nanoparticles.

\section{MATERIAL AND METHODS}

Plant materials: Eight plants were evaluated in the present study for the management of Aedes aegypti. The test plants include neem, ginger, bakain, eucalyptus, garlic, clove, datura and bitter gourd. The lethal effects of these plants and their silver synthesized nanoparticles were tested against $3^{\text {rd }}$ and $4^{\text {th }}$ instars larvae of $A$. aegypti.

Preparation of botanical extracts: Fresh parts of test plants were thoroughly washed with clean water to remove any dirt or other materials attached to them and dried up on a plastic sheet under shade for three weeks. The plant materials were crushed separately into powdered form and passed through a 20 mesh sieve. Hundred grams of each powdered material was dissolved into half liter of $99 \%$ ethanol serving as stock solution and different concentrations were made. The stock solution was poured into a conical flask and covered with aluminum foil. The solution was manually twice mixed every day by shaking for an entire week and then filtered through Whatman No.1 filter paper. The filtered extract solution was again collected in a separate conical flask.

The stock solution was stored at $5^{\circ} \mathrm{C}$ in a freezer. The extract was then converted into the crude extract form by placing it in an electric rotary evaporator at $78^{\circ} \mathrm{C}$. After the ethanol had evaporated, the crude extract of the plant material left behind. This was collected in a beaker and placed at room temperature to ensure that the remaining moisture dried up. After 24 hours, the extract was removed from the beaker, weighed, and then stored at $4^{\circ} \mathrm{C}$ in a freezer for use. The same procedure was repeated three times to obtain the crude plant extracts of all the plants. The entire procedure was conducted according to the methodology mentioned by Minjas and Sarda (1986).

\section{Synthesis of green silver nanoparticles:}

After the crude extracts of eight plants had been prepared according to the above given procedure, these were then used to prepare the green silver nanoparticles tested in this study. Ten grams of the crude extract from each plant was taken and dissolved in $250 \mathrm{ml}$ of distilled water. This was then boiled for five minutes and passed through Whatman No. 1 filter paper. The filtrate was separately stored for further use. Silver nitrate $\left(\mathrm{AgNO}_{3}\right)$ was prepared by taking $100 \mathrm{ml}$ of distilled water and then dissolving $1 \mathrm{mM}$ of silver nitrate salt in it. The solution was poured into a beaker up to $80 \mathrm{ml}$ and the remaining $20 \mathrm{ml}$ was discarded. It was then mixed on a hot plate magnetic stirrer and the previously prepared 
crude extract filtrate was added to it. The hot plate was set to $100^{\circ} \mathrm{C}$ for five minutes in order to boil the solution. After five minutes, the solution's color changed to brown which indicated that the silver nanoparticle formation had concluded. The brown liquid was then poured into falcon tubes for centrifugation at $5000 \mathrm{rpm}$ for a period of 15 minutes. Excess solution was removed from the falcon tubes and the remainder was transformed into pellets which were placed in a china dish. The dish was then heated in an oven at $50^{\circ} \mathrm{C}$ for 24 hours in order to remove moisture from the pellets. Once they were dried, the pellets were manually ground up using a pestle and mortar. Eppendorf tubes were used to store the pulverized powder after which they were covered with aluminum paper and labelled accordingly. The procedure was done according to the methodology described by Parashar et al. (2009).

Rearing of larvae of A. aegypti: The larvae of $A$. aegypti were collected from the National Institute of Health Sciences Islamabad and brought to the Insect Molecular Biology laboratory, Department of Entomology, Arid Agriculture University, Rawalpindi. The larvae were reared in plastic trays which were maintained in rearing jars. The front side of rearing cage was covered with a muslin cloth for aeration and feeding. The larvae were fed on commercial based beef liver powder. A temperature of $25^{\circ} \mathrm{C}$ and a relative humidity of $85 \%$ were maintained in the laboratory.

Assessment of botanical extracts and green synthesized Ag-nanoparticles against A. aegypti: A total of six concentrations of plant extracts with five replications were assessed against $3^{\text {rd }}$ and $4^{\text {th }}$ larval instars of $A$. aegypti. The bioassays were performed in plastic dishes and mortalities were recorded after 24,48 , and 72 hours of treatment. The concentrations were recorded as $\mathrm{C} 1$ to $\mathrm{C} 5$ and control was referred to as $\mathrm{C} 0$. C1 denoted the lowest concentration value while C5 represented the highest one. The same procedure was followed for the evaluation of green synthesized Agnanoparticles.

Statistical analysis: $\mathrm{LC}_{50}$ values were calculated using probit analysis. The percentage corrected mortality of mosquito larvae was calculated using Abbot's formula (Abbott, 1925). R statistical software was used for data analysis. Probit analysis was conducted using Polo-plus software.

\section{RESULTS}

Larvicidal potential of plant extracts against $3^{\text {rd }}$ and $4^{\text {th }}$ instar larvae of $\boldsymbol{A}$. aegypti: Clove extracts caused the maximum mortalities of $92 \%$ and $90 \%$ of $3^{\text {rd }}$ and $4^{\text {th }}$ instar larvae of $A$. aegypti followed by ginger causing $90 \%$ and $78 \%$ mortalities respectively. On the other hand, the minimum mortalities of these larvae were caused by neem and garlic extracts (Table 1).

Table 1: Percent mortality of $3^{\text {rd }}$ and $4^{\text {th }}$ instars of Aedes aegypti with the highest concentrations of plant extracts and green synthesized nanoparticles after 72 hours.

\begin{tabular}{lllll}
\hline $\begin{array}{l}\text { Botanical } \\
\text { used }\end{array}$ & \multicolumn{2}{l}{$\begin{array}{l}\text { Mortality of A. aegypti with botanical } \\
\text { extracts against }\end{array}$} & \multicolumn{2}{c}{$\begin{array}{l}\text { Mortality of A. aegypti with } \\
\text { green nanoparticles against }\end{array}$} \\
\cline { 2 - 5 } & $3^{\text {rd }}$ instar & $4^{\text {th }}$ instar & $3^{\text {rd }}$ instar & $4^{\text {th }}$ instar \\
\hline Neem & $72 \%$ & 72 & 94 & $82 \%$ \\
Ginger & $90 \%$ & 78 & 96 & $88 \%$ \\
Bitter gourd & $84 \%$ & 76 & 92 & $72 \%$ \\
Eucalyptus & $80 \%$ & 76 & 90 & $82 \%$ \\
Datura & $84 \%$ & 72 & 74 & $80 \%$ \\
Clove & $92 \%$ & 90 & 98 & $90 \%$ \\
Bakain & $80 \%$ & 74 & 92 & $82 \%$ \\
Garlic & $72 \%$ & 70 & 86 & $80 \%$ \\
\hline
\end{tabular}

Larvicidal potential of plant based nanoparticles against $3^{\text {rd }}$ and $4^{\text {th }}$ instar larvae of $A$. aegypti: In case of green silver nanoparticles, the maximum mortalities of $3^{\text {rd }}$ and $4^{\text {th }}$ instar larvae of $A$. aegypti were caused by clove followed by ginger while the minimum mortalities were caused by nanoparticles of datura followed by garlic. All the green silver nanoparticles caused mortalities of both the instars of the mosquito above $80 \%$ with few exceptions (Table 1).

LC 50 values of plant extracts against $3^{\text {rd }}$ and $4^{\text {th }}$ instar larvae of $\boldsymbol{A}$. aegypti: The $\mathrm{LC}_{50}$ values of plant extracts against $3^{\text {rd }}$ instar larvae are shown in Table 2. 
Datura extracts showed the minimum $\mathrm{LC}_{50}$ values after 72 hours of application followed by neem against the $3^{\text {rd }}$ instar $A$. aegypti larvae. The $\mathrm{LC}_{50}$ values decreased with an increase in the time. The highest
$\mathrm{LC}_{50}$ value was observed in case of ginger followed by clove and eucalyptus as shown in Table 2. Similar trend of $\mathrm{LC}_{50}$ values was observed in case of $4^{\text {th }}$ instar larvae (Table 3).

Table 2: $\mathrm{LC}_{50}$ values of plant extracts at three time intervals against $3^{\text {rd }}$ instar larvae of Aedes aegypti.

\begin{tabular}{lccc}
\hline Plant extract $(\mathrm{mg} / \mathrm{L})$ & \multicolumn{3}{c}{ LC 50 with fiducial limit at } \\
\cline { 2 - 4 } & 24 hours & 48 hours & 72 hours \\
\hline Ginger & 276.640 & 236.788 & 209.632 \\
& $248.324-309.933$ & $213.058-258.178$ & $181.439-230.950$ \\
Garlic & 68.09 & 61.75 & 46.04 \\
& $61.17-78.74$ & $54.56-72.43$ & $38.30-54.03$ \\
Neem & 24.475 & 22.494 & 19.206 \\
& $22.477-27.510$ & $20.340-25.431$ & $16.433-21.670$ \\
Bakain & 37.415 & 30.681 & 24.911 \\
& $32.972-43.269$ & $25.622-35.891$ & $18.690-29.8473$ \\
Bitter gourd & 195.892 & 158.703 & 125.985 \\
& $171.394-234.192$ & $137.804-185.192$ & $106.103-146.131$ \\
Clove & 378.741 & 317.073 & 225.291 \\
& $339.008-429.678$ & $274.980-362.059$ & $174.681-265.229$ \\
Eucalyptus & 322.550 & 254.184 & 208.353 \\
& $281.748-381.839$ & $216.854-298.708$ & $170.724-245.883$ \\
Datura & 0.439 & 0.378 & 0.305 \\
& $0.394-0.505$ & $0.333-0.438$ & $0.263-0.348$ \\
\hline
\end{tabular}

Table 3: LC50 values of plant extracts at three time intervals against $4^{\text {th }}$ instar larvae of Aedes aegypti.

\begin{tabular}{lccc}
\hline Plant extract $(\mathrm{mg} / \mathrm{L})$ & \multicolumn{3}{c}{ LC 50 with fiducial limit at } \\
\cline { 2 - 4 } & 24 hours & 48 hours & 72 hours \\
\hline Ginger & 307.758 & 262.717 & 216.522 \\
& $281.047-350.246$ & $235.843-293.170$ & $178.071-243.943$ \\
Garlic & 72.92 & 63.34 & 52.33 \\
& $65.98-8.399$ & $56.82-7.276$ & $45.84-6.013$ \\
Neem & 26.394 & 22.566 & 19.565 \\
& $24.184-30.153$ & $20.495-25.357$ & $17.117-21.867$ \\
Bakain & 44.165 & 35.130 & 27.063 \\
& $38.913-52.711$ & $29.261-42.978$ & $20.552-32.618$ \\
Bitter gourd & 223.356 & 183.159 & 138.195 \\
& $194.825-273.252$ & $150.940-241.615$ & $113.353-166.423$ \\
Clove & 443.163 & 302.493 & 230.907 \\
& $392.380-524.221$ & $258.802-346.784$ & $177.686-272.912$ \\
Eucalyptus & 371.031 & 307.650 & 209.013 \\
& $323.842-447.876$ & $261.255-377.914$ & $166.707-251.618$ \\
Datura & 0.473 & 0.422 & 0.341 \\
& $0.427-0.547$ & $0.369-0.505$ & $0.290-0.403$ \\
\hline
\end{tabular}

LC $_{50}$ values of plant-based Ag-nanoparticles against $3^{\text {rd }}$ and $4^{\text {th }}$ instar larvae of $\boldsymbol{A}$. aegypti: The $\mathrm{LC}_{50}$ values of the green synthesized silver nanoparticles used against $3^{\text {rd }}$ instar larvae are shown in Table 4. The 
minimum $\mathrm{LC}_{50}$ values after 72 hours were recorded in case of datura, neem and garlic while the values were the maximum in case of clove and ginger. A similar trend was found in case of $4^{\text {th }}$ instar larvae. On the other hand, the maximum values were observed with clove and ginger. The $\mathrm{LC}_{50}$ values decreased with the passage of time. The values were the maximum after 24 hours and decreased as the time interval increased (Table 5).

Table 4: LC50 values of green synthesized Ag-nanoparticles at three time intervals against $3^{\text {rd }}$ instar larvae of Aedes aegypti.

\begin{tabular}{lccc}
\hline Plant extract (mg/L) & \multicolumn{3}{c}{ LC 50 with fiducial limit at } \\
\cline { 2 - 4 } & 24 hours & 48 hours & 72 hours \\
\hline Ginger & 46.798 & 39.743 & 31.696 \\
& $41.417-51.481$ & $31.46-44.338$ & $22.901-36.953$ \\
Garlic & 11.023 & 9.687 & 6.769 \\
& $9.475-13.136$ & $8.210-11.332$ & $4.904-8.162$ \\
Neem & 4.109 & 3.501 & 2.795 \\
& $3.709-4.533$ & $3.006-3.881$ & $2.170-3.189$ \\
Bakain & 6.141 & 4.427 & 3.916 \\
& $5.068-7.251$ & $3.139-5.371$ & $2.641-4.813$ \\
Bitter gourd & 34.408 & 24.253 & 15.011 \\
& $28.983-42.703$ & $18.841-29.510$ & $8.554-19.560$ \\
Clove & 61.574 & 46.570 & 33.899 \\
& $53.442-69.973$ & $36.377-54.720$ & $9.017-46.885$ \\
Eucalyptus & 52.344 & 38.279 & 17.973 \\
& $43.965-62.950$ & $28.809-47.029$ & $2.947-27.305$ \\
Datura & 0.076 & 0.061 & 0.044 \\
& $0.068-0.087$ & $0.051-0.072$ & $0.030-0.054$ \\
\hline
\end{tabular}

Table 5: LC50 values of green synthesized Ag-nanoparticles at three time intervals against $3^{\text {rd }}$ instar larvae of Aedes aegypti.

\begin{tabular}{lccc}
\hline Plant extract (mg/L) & \multicolumn{3}{c}{ LC 50 with fiducial limit at } \\
\cline { 2 - 4 } & 24 hours & 48 hours & 72 hours \\
\hline Ginger & 53.729 & 39.738 & 35.790 \\
& $48.249-60.363$ & $30.891-45.312$ & $27.100-41.105$ \\
Garlic & 13.052 & 11.218 & 6.769 \\
& $11.657-15.167$ & $9.885-12.977$ & $4.904-8.162$ \\
Neem & 4.595 & 3.862 & 3.165 \\
& $4.203-5.130$ & $3.404-4.282$ & $2.437-3.618$ \\
Bakain & 7.688 & 5.841 & 3.594 \\
& $6.548-9.425$ & $4.512-7.108$ & $1.222-4.888$ \\
Bitter gourd & 39.183 & 30.952 & 22.810 \\
& $33.280-49.486$ & $25.450-38.443$ & $14.799-29.712$ \\
Clove & 79.183 & 53.106 & 37.943 \\
& $68.167-96.217$ & $39.637-64.372$ & $23.551-47.609$ \\
Eucalyptus & 63.474 & 49.399 & 31.173 \\
& $54.262-77.609$ & $40.969-59.492$ & $19.322-40.270$ \\
Datura & 0.085 & 0.072 & 0.054 \\
& $0.075-0.100$ & $0.061-0.087$ & $0.042-0.064$ \\
\hline
\end{tabular}

\section{DISCUSSION}

In the current study, all the plant extracts caused $50 \%$ mortalities of $3^{\text {rd }}$ and $4^{\text {th }}$ instar larvae of $A$. aegypti while Ag-nanoparticles of these plants gave even higher mean 
mortality values. $4^{\text {th }}$ instar larvae were found resistant to plant extracts and nanoparticles as compared to $3^{\text {rd }}$ instar larvae of the mosquito.

The mortalities caused by plant extracts and green sliver nanoparticles could be attributed to certain insecticidal and insect repellant compounds found in the green synthesized silver nanoparticles of the plants. The clove plant contains the chemical eugenol which is known for its medicinal and antibiotic potential. Medeiros et al. (2013) evaluated the larvicidal potential of clove extracts and eugenol against two mosquito species i.e. Anopheles darlingi and A. aegypti. The results showed that $A$. aegypti was 63 times more susceptible to clove extracts as compared to $A$. darlingi larvae. Similarly, bakain showed good larvicidal potential and required a relatively large concentration to kill $50 \%$ of the mosquito population in the present study. The results are supported by the study of Selvaraj and Mosses (2011) who evaluated the efficacy of bakain on three different mosquito species i.e. A. aegypti, Culex quinquefasciatus, and $A$. stephensi. The dengue mosquito species was found to be the most resistant to bakain extracts. The other two species showed very similar levels of susceptibility.

Ginger was found to cause the maximum mortality of mosquitos. Similar results were obtained by Nasir et al. (2017) who tested different plant extracts and confirmed that Zingiber officinale had the highest effectiveness in inducing mean mortality in immature $A$. albopictus larvae. The $3^{\text {rd }}$ instar larvae were the least resistant to plant extracts as compared to $4^{\text {th }}$ instar larvae. It was also found that plant oils of eucalyptus gave the highest mean mortality and that of ginger the lowest. The study also showed that Azadirachta indica extracts gave the highest $\mathrm{LC}_{50}$ values of all the test plants. In the present study, bitter gourd and eucalyptus extracts proved to be less effective against $A$. aegypti larvae. The present results were in contrast to those reported by Singh et al. (2006) in which they treated the $4^{\text {th }}$ instars of three different mosquito species with crude fruit extracts of Momordica charantia and obtained good results.

Eucalyptus was also an average performer in the current study, giving similar results to bitter gourd. A study conducted by Nair et al. (2014) also reported the larvicidal potential of leaf extracts of eucalyptus as well as of the medicinal plant Centella asiatica. According to these authors, eucalyptus was not as effective as its counterpart in inducing mean mortality in the targeted mosquito species i.e. A. aegypti and A. stephensi.

The extracts and Ag-nanoparticles of garlic did not perform well in this study against $A$. aegypti mosquito larvae. Garlic had by far the highest amount required to reach the $\mathrm{LC}_{50}$ value. These results conformed to the findings of Selvam and Durai (2018)Selvam and Durai (2018) who evaluated the larvicidal potential of 11 different plant extracts against A. albopictus and an unspecified species of Anopheles. In their study, Allium sativum bulb extracts in ethyl alcohol gave the worst performance out of all the 11 test plant extracts. Conversely, the extracts of $A$. indica showed the best larvicidal potential. As these were the only two plants out of the 11 used in this study which were the same as the plants used in the current study. In another study, Ali et al. (2017) tested five plants against $A$. aegypti larvae. Neem showed the highest larvicidal potential whereas eucalyptus did not prove effective and confirmed the present findings.

In all cases, the Ag-nanoparticles outperformed their plant extract counterparts in causing larval mean mortality of both the larval instars. The effectiveness of Ag-nanoparticles against A. albopictus larvae has previously been demonstrated by Ga'al et al. (2018). They utilized three different types of silver nanoparticles: first was artificially fabricated while the other two were synthesized using Salicylic acid and 3, 5dinitrosalicylic acid respectively. It was found that the artificially synthesized Ag-nanoparticles proved to be highly toxic to dengue mosquito larvae as compared to the ones derived from Salicylic acid whereas the ones derived from 3, 5-dinitrosalicylic acid did not cause significant mortality. It is therefore, concluded that the artificially synthesized Ag-nanoparticles can be used as an environmentally friendly alternative insecticide for the management of $A$. aegypti.

\section{CONFLICT OF INTEREST}

The authors declare no conflict of interest.

\section{AUTHORS' CONTRIBUTION}

HS, MT and AG designed the study, HS and MSB conducted the experiments and collected data, MT and ZRM analyzed the data, MT supervised the work, HS and MT wrote the manuscript and all the authors edited and approved the final manuscript.

\section{REFERENCES}

Abbas, A., Abbas, R.Z., Khan, J.A., Iqbal, Z., Bhatti, H., Mehmood, M., Zia, M.A., 2014. Integrated 
strategies for the control and prevention of dengue vectors with particular reference to Aedes aegypti. Pakistan Veterinary Journal 34, 1-10.

Abbott, W.S., 1925. A method of computing the effectiveness of an insecticide. Journal of Economic Entomology 18, 165-167.

Ali, M., Khan, H.A.A., Tahir, H.M., Tariq, A., Ashfaq, M., Ali, S.W., Gulzar, A., Aslam, H.U.A., Khalid, U., Yousaf, S., Mubashar, U., 2017. Larvicidal potenial of diffrent plants extracts against the larvae of mosquito Aedes aegypti (L.) (Culicidae: Diptera). Pakistan Entomologist 39, 37-40.

Barnawi, A.A.B., Sharawi, S.E., Mahyoub, J.A., Al-Ghamdi, K.M., 2019. Larvicidal studies of Avicennia marina extracts against the dengue fever mosquito Aedes aegypti (Culicidae: Diptera). International Journal of Mosquito Research 6, 55-60.

Fouad, H., Hongjie, L., Hosni, D., Wei, J., Abbas, G., Ga'al, H., Jianchu, M., 2018. Controlling Aedes albopictus and Culex pipiens pallens using silver nanoparticles synthesized from aqueous extract of Cassia fistula fruit pulp and its mode of action. Artificial Cells, Nanomedicine and Biotechnology 46, 558-567.

Ga'al, H., Fouad, H., Tian, J., Hu, Y., Abbas, G., Mo, J., 2018. Synthesis, characterization and efficacy of silver nanoparticles against Aedes albopictus larvae and pupae. Pesticides Biochemistry and Physiology 144, 49-56.

Ghosh, A., Chowdhury, N., Chandra, G., 2012. Plant extracts as potential mosquito larvicides. Indian Journal of Medical Research 135, 581-598.

Gutiérrez-Bugallo, G., Piedra, L.A., Rodriguez, M., Bisset, J.A., Lourenço-de-Oliveira, R., Weaver, S.C., Vasilakis, N., Vega-Rúa, A., 2019. Vector-borne transmission and evolution of Zika virus. Nature Ecology and Evolution 1, 561-569.

Hazra, D.K., Samanta, A., Karmakar, R., Sen, K., Bakshi, P., 2017. Mosquito vector management knowledge, attitude, practices and future of user \& environment friendly new generation botanical mosquitocide formulations. A review. International Journal of Chemical Studies 5, 32-37.

Iravani, S., 2011. Green synthesis of metal nanoparticles using plants. Green Chemistry 13, 2638-2650.

Kandel, Y., Vulcan, J., Rodriguez, S.D., Moore, E., Chung, H.N., Mitra, S., Ettestad, P., Hansen, I.A., 2019. Widespread insecticide resistance in Aedes aegypti
L. from New Mexico, USA. PloS One 14, 1-16.

Leparc-Goffart, I., Nougairede, A., Cassadou, S., Prat, C., De Lamballerie, X., 2014. Chikungunya in the Americas. The Lancet 383, 514.

Li, R., Xu, L., Bjørnstad, O.N., Liu, K., Song, T., Chen, A., Stenseth, N.C., 2019. Climate-driven variation in mosquito density predicts the spatiotemporal dynamics of dengue, Proceedings of the National Academy of Sciences of the United States of America, pp. 3624-3629.

Manjarres-Suarez, A., Olivero-Verbel, J., 2013. Chemical control of Aedes aegypti: a historical perspective. Revista Costarricense de Salud Pública 22, 68-75.

Medeiros, E.D.S., Rodrigues, I.B., Litaiff-Abreu, E., da S Pinto, A.C., Tadei, W.P., 2013. Larvicidal activity of clove (Eugenia caryophyllata) extracts and eugenol against Aedes aegypti and Anopheles darlingi. African Journal of Biotechnology 12, 836840.

Minjas, J.N., Sarda, R.K., 1986. Laboratory observations on the toxicity of Swartzia madagascariensis (Leguminosae) extract to mosquito larvae. Transactions of the Royal Society of Tropical Medicine and Hygiene 80, 60-461.

Misni, N., Sulaiman, S., Othman, H., Omar, B., 2009. Repellency of essential oil of Piper aduncum against Aedes albopictus in the laboratory. Journal of the American Mosquito Control Association 25, 442-448.

Morrison, A.C., Schwarz, J., Long, K.C., Cordova, J., Rios, J.E., Quiroz, W.L., Vizcarra, S.A., Hontz, R.D., Scott, T.D., Lambrechts, L., Paz Soldan, V.A., Soldan, V.A.P., 2019. Acceptability of Aedes aegypti blood feeding on dengue virus-infected human volunteers for vector competence studies in Iquitos, Peru. PLOS Neglected Tropical Diseases 13, 1-20.

Nair, S.S., Shetty, V., Shetty, N.J., 2014. Relative toxicity of leaf extracts of Eucalyptus globulus and Centella asiatica against mosquito vectors Aedes aegypti and Anopheles stephensi. Journal of Insects Article ID $985463, \quad 7 \quad$ pages https://doi.org/10.1155/2014/985463.

Nasir, S., Nasir, I., Asrar, M., Debboun, M., 2017. Larvicidal and pupicidal action of medicinal plant extracts against dengue mosquito Aedes albopictus (Skuse) (Diptera: Culicidae). Indian Journal of Animal Research 51, 155-158. 
Pandiyan, G.N., Mathew, N., Munusamy, S., 2019. Larvicidal activity of selected essential oil in synergized combinations against Aedes aegypti. Ecotoxicology and Environmental Safety 174, 549556.

Parashar, U.K., Saxena, P.S., Srivastava, A., 2009. Bioinspired synthesis of silver nanoparticles. Digest Journal of Nanomaterials and Biostructures 4, 159-166.

Paul, A., Harrington, L.C., Scott, J.G., 2006. Evaluation of novel insecticides for control of dengue vector Aedes aegypti (Diptera: Culicidae). Journal of Medical Entomology 43, 55-60.

Pavunraj, M., Baskar, K., Duraipandiyan, V., Al-Dhabi, N.A., Rajendran, V., Benelli, G., 2017. Toxicity of Ag nanoparticles synthesized using stearic acid from Catharanthus roseus leaf extract against Earias vittella and mosquito vectors (Culex quinquefasciatus and Aedes aegypti). Journal of Cluster Science 28, 2477-2492.

Remia, K., Logaswamy, S., Shanmugapriyan, R., 2017. Efficacy of botanical repellents against Aedes aegypti. International Journal of Mosquito Research 4, 126-129.

Sangat-Roemantyo, H., 1990. Ethnobotany of the Javanese incense. Economic Botany 44, 413-416.

Selvam, J., Durai, M., 2018. Phytochemical analysis and larvicidal activity of aqueous and ethanol extract of selective medicinal plants against malaria and dengue vector. International journal of Science Research 9, 27113-27119.

Selvaraj, M., Mosses, M., 2011. Efficacy of Melia azedarach on the larvae of three mosquito species Anopheles stephensi, Culex quinquefasciatus and Aedes aegypti (Diptera: Culicidae). European Mosquito Bulletin 29, 116-121.

Singh, R., Dhiman, R., Mittal, P., 2006. Mosquito larvicidal properties of Momordica charantia Linn (Family: Cucurbitaceae). Journal of Vector Borne Diseases $43,88$.

Suresh, G., Gunasekar, P.H., Kokila, D., Prabhu, D., Dinesh, D., Ravichandran, N., Balasubramanian, R., Arunagirinathan, K., Siva, G.V., 2014. Green synthesis of silver nanoparticles using Delphinium denudatum root extract exhibits antibacterial and mosquito larvicidal activities. Spectrochimica Acta Part A: Molecular and Biomolecular Spectroscopy 127, 61-66.

Vasantha-Srinivasan, P., Karthi, S., Chellappandian, M., Ponsankar, A., Thanigaivel, A., Senthil-Nathan, S., Ganesan, R., 2019. Aspergillus flavus (Link) toxins reduces the fitness of dengue vector Aedes aegypti (Linn.) and their non-target toxicity against aquatic predator. Microbial Pathogenesis 128, 281-287.

WHO, 2018. Dengue and severe dengue. 